\title{
Axon Branching and Synaptic Bouton Phenotypes in GABAergic Nonpyramidal Cell Subtypes
}

\author{
Fuyuki Karube, Yoshiyuki Kubota, and Yasuo Kawaguchi \\ Division of Cerebral Circuitry, National Institute for Physiological Sciences, Okazaki 444-8585, Japan
}

\begin{abstract}
GABAergic nonpyramidal cells, cortical interneurons, consist of heterogeneous subtypes differing in their axonal field and target selectivity. It remains to be investigated how the diverse innervation patterns are generated and how these spatially complicated, but synaptically specific wirings are achieved. Here, we asked whether a particular cell type obeys a specific branching and bouton arrangement principle or differs from others only in average morphometric values of the morphological template common to nonpyramidal cells. For this purpose, we subclassified nonpyramidal cells within each physiological class by quantitative parameters of somata, dendrites, and axons and characterized axon branching and bouton distribution patterns quantitatively. Each subtype showed a characteristic set of vertical and horizontal bouton spreads around the somata. Each parameter, such as branching angles, internode or interbouton intervals, followed its own characteristic distribution pattern irrespective of subtypes, suggesting that nonpyramidal cells have the common mechanism for formation of the axon branching pattern and bouton arrangement. Fitting of internode and interbouton interval distributions to the exponential indicated their apparent random occurrence. Decay constants of the fitted exponentials varied among nonpyramidal cells, but each subtype expressed a particular set of interbouton and internode interval averages. The distinctive combination of innervation field shape and local axon phenotypes suggests a marked functional difference in the laminar and columnar integration properties of different GABAergic subtypes, as well as the subtype-specific density of inhibited targets.
\end{abstract}

Key words: frontal cortex; interneuron; GABA; synaptic bouton; fast-spiking cell; late-spiking cell

\section{Introduction}

Because the cerebral cortex is composed of heterogeneous cell populations, objective classification of neurons is necessary for analyzing and modeling cortical circuitry. The cerebral cortex contains two major neuronal cell types, excitatory pyramidal cells using glutamate and inhibitory nonpyramidal cells synthesizing GABA as a neurotransmitter (Ribak, 1978; Houser et al., 1983; DeFelipe and Fariñas, 1992; Amitai and Connors, 1995). Pyramidal cells are arranged in a layered manner and can be classified into subtypes based on differences in their projection sites (Jones, 1984b). GABAergic nonpyramidal cells, cortical interneurons, display a variety of morphological forms that have been used for their morphological classification (Ramón y Cajal, 1911; Jones, 1975; Feldman and Peters, 1978; Fairén et al., 1984). Physiologically, nonpyramidal cells can be divided into several groups by their firing characteristics (Kawaguchi, 1993, 1995, 2001; Thomson et al., 1996; Cauli et al., 1997, 2000; Gupta et al., 2000). In addition, particular calcium-binding proteins and neuropeptides

Received Aug. 19, 2003; revised Feb. 2, 2004; accepted Feb. 3, 2004

This work was supported by grants-in-aid for scientific research from the Ministry of Education, Culture, Sports, Science and Technology of Japan; the Daiko Foundation; the Japan Epilepsy Research Foundation; and the Toyota Physical and Chemical Research Institute. We thank Y. Ito and M. Saito for technical assistance and Drs. A. Agmon and S. Kondo for comments. We thank Dr. Y. Sakai for helpful discussion and MicroBrightField for technical support. We are grateful to Dr. L. Tettoni for providing the program for measuring the interbouton interval and to Dr. W. Vale for an antiserum against corticotropin-releasing factor.

Correspondence should be addressed to Dr. Yasuo Kawaguchi, Division of Cerebral Circuitry, National Institute for Physiological Sciences, Myodaiji, 0kazaki 444-8585, Japan. E-mail: yasuo@nips.ac.jp.

DOI:10.1523/JNEUROSCI.4814-03.2004

Copyright $\odot 2004$ Society for Neuroscience $\quad$ 0270-6474/04/242853-13\$15.00/0 are expressed in separate groups of GABA cells (Kubota et al., 1994; DeFelipe, 1997; Gonchar and Burkhalter, 1997; Kawaguchi and Kubota, 1997). Previously, we found that a group of nonpyramidal cells in the rat frontal cortex, which has a unique combination of firing patterns and molecular markers, will display a few specific morphological forms (Kawaguchi and Kubota, 1996, 1998; Kawaguchi and Kondo, 2002; Kawaguchi, 2003). However, morphological classification in these studies was based on qualitative appearances. For objective classification, quantification of morphological characteristics is necessary (Wang et al., 2002); a quantitative procedure may reveal stereotypy of cellular composition common to diverse cortical areas (Silberberg et al., 2002).

GABAergic nonpyramidal cells seem to be diverse in the direction, spatial spread and density of their axonal innervation (White, 1989). Different nonpyramidal cell subtypes are known to make synapses on particular membrane domains of the postsynaptic neurons (Somogyi et al., 1998), suggesting a process of specific target selection during axonal growth. It remains to be investigated how these spatially complicated, but synaptically specific, wirings are achieved. The overall innervation pattern depends on the manner of axonal outgrowth and branching and on the arrangement of presynaptic specializations along the axon (Hellwig et al., 1994; Braitenberg and Schütz, 1998; Anderson et al., 2002). Understanding the mechanisms generating these diverse innervation patterns and the selection of specific postsynaptic targets requires unraveling the rules of axon branching and presynaptic bouton formation in each subtype. These differences among subtypes will shed light on the functional role of each in the cortical circuitry. 
Here, we asked whether a particular cell type obeys a specific branching and bouton arrangement principle or differs from others only in average morphometric values of the template common to nonpyramidal cells. For this purpose, we subclassified nonpyramidal cells within each physiological class by gross morphological parameters of somata, dendrites, and axons, followed by analyzing local axon characteristics and comparing them among above subtypes. We found the distribution-type similarity of local parameters and the difference in combinations of their average values among subtypes.

\section{Materials and Methods}

Electrophysiology. The experiments were performed on young Wistar rats (19-23 d postnatal). Animals were deeply anesthetized with isoflurane and decapitated. The brains were removed quickly and submerged in ice-cold physiological Ringer's solution. Sections of frontal cortex (medial agranular cortex and anterior cingulate cortex) were cut at a thickness of $300 \mu \mathrm{m}$ and immersed in a buffered solution (in mM: $124.0 \mathrm{NaCl}$, $3.0 \mathrm{KCl}, 2.4 \mathrm{CaCl}_{2}, 1.2 \mathrm{MgCl}_{2}, 26.0 \mathrm{NaHCO}_{3}, 1.0 \mathrm{NaH}_{2} \mathrm{PO}_{4}$, and 10.0 glucose, aerated with a mixture of $95 \% \mathrm{O}_{2}$ and $5 \% \mathrm{CO}_{2}$ ).

Cortical cells were recorded in a whole-cell mode at $30-31^{\circ} \mathrm{C}$ using a $40 \times$ water immersion objective. The electrode solution for the currentclamp recording consisted of (in $\mathrm{mM}$ ) 120 potassium methylsulfate, 5.0 $\mathrm{KCl}, 0.6 \mathrm{EGTA}, 2 \mathrm{MgCl}_{2}, 4.0$ ATP, $0.3 \mathrm{GTP}, 10 \mathrm{HEPES}$, and 17 biocytin. The $\mathrm{pH}$ of the solution was adjusted to 7.3 with $\mathrm{KOH}$, and the osmolarity was to $290 \mathrm{mOsm}$. Current-clamp recordings were made in the fast current-clamp mode of EPC9 (HEKA, Lambrecht/Pfalz, Germany) or in the bridge mode of an Axoclamp-2B amplifier (Axon Instruments, Foster City, CA). The duration of recording time was 10-20 min. Input resistances of cells were determined by linear regression of zero and three voltage shifts up to $20 \mathrm{mV}$ negative to rest induced by hyperpolarizing current pulses (duration, 500-600 msec) and by subtraction of the series resistance. Membrane time constants were determined by passing hyperpolarizing current pulses inducing voltage shifts of $6-15 \mathrm{mV}$ negative to rest. Spike widths at half amplitude were measured for spikes elicited within $10 \mathrm{msec}$ by depolarizing current pulses. Spike afterhyperpotentials were measured from the spike onset potential. The generation of two or more spikes on slow humps from hyperpolarization (burst spiking) was investigated by depolarizing current pulses of threshold strength from -75 to $-85 \mathrm{mV}$. Electrophysiological data were analyzed by IGOR Pro (WaveMetrics, Lake Oswego, OR).

Histology and immunohistochemistry. Tissue slices containing biocytin-loaded cells were fixed by immersion in $4 \%$ paraformaldehyde, $1.25 \%$ or $0.05 \%$ glutaraldehyde, and $0.2 \%$ picric acid overnight at $4^{\circ} \mathrm{C}$ and followed by a freeze-thawing procedure in sucrose-containing phosphate buffer $(\mathrm{PB})$ using liquid nitrogen twice. Slices were cut at thickness of $50 \mu \mathrm{m}$.
Each slice (a set of sections) was further treated by one of the following two procedures.

(1) Some slices were incubated with avidin-biotin-peroxidase complex (1:100; Vector Laboratories, Burlingame, CA) in 0.05 м Tris HClbuffered saline (TBS) with or without $0.04 \%$ Triton X-100 (TX) overnight at $4^{\circ} \mathrm{C}$. After washing in TBS, the slices were reacted with DAB $(0.05 \%)$ and $\mathrm{H}_{2} \mathrm{O}_{2}(0.003 \%)$ in Tris- $\mathrm{HCl}$ buffer.

(2) The other slices were processed for fluorescence immunohistochemistry. The slices were incubated with the primary antibodies in TBS containing $2 \%$ BSA, $10 \%$ NGS or normal horse serum (NHS), and $0.5 \%$ (or $0.04 \%$ ) TX. After washing in TBS, they were incubated in fluorescent secondary antibodies [conjugated with dichlorotriaginyl amino fluorescein (Chemicon, Temecula, CA), tetramethylrhodamine (Chemicon), or Texas Red (Amersham)] in TBS containing BSA, NGS (or NHS), and TX for $4 \mathrm{hr}$, followed by incubation with Alexa 350 streptavidin (1:1000; S-11249; Molecular Probes, Eugene, OR) in TBS for 1 hr. After examination for fluorescence, the slices were incubated with avidin-biotin-peroxidase complex in TBS and reacted with $\mathrm{DAB}$ and $\mathrm{H}_{2} \mathrm{O}_{2}$ in Tris- $\mathrm{HCl}$ buffer. They were then postfixed in $1 \% \mathrm{OsO}_{4}$ in $\mathrm{PB}$, dehydrated, and flat-embedded on silicon-coated glass slides in Epon.

A mouse monoclonal antibody raised against cholecystokinin (CCK)/ gastrin (catalog \#28.2 MoAb; dilution, 1:4000) was provided by CURE/ UCLA/Digestive Diseases Research Center Antibody/RIA Core (Los Angeles, CA). A rat monoclonal antibody against somatostatin (MAB354; 1:250) was purchased from Chemicon. A rabbit antiserum against vasoactive intestinal polypeptide (VIP) (catalog \#20077; 1:1000) was obtained from DiaSorin (Stillwater, MN). A rabbit antiserum against corticotropin-releasing factor (CRF; 1:4000) was kindly provided by Dr. Wylie Vale (Salk Institute, La Jolla, CA). A goat antiserum against calretinin (code number CG1; 1:2500) was obtained from SWant (Bellinzona, Switzerland).

After fixation, dehydration, and embedding in Epon, slices shrank to $\sim 90 \%$ in length $(87 \pm 4 \%$ in slice flat surface and $90 \pm 2 \%$ in slice thickness; 11 slices). The shrinkage was not corrected in the analysis.

Quantitative morphology. Somata, axons, dendrites, boutons, and spines of stained cells were reconstructed three-dimensionally, using the Neurolucida system (MicroBrightField, Williston, VT). Stained cells were drawn with $60 \times$ or $100 \times$ objectives, combined with an additional $1.25 \times$ magnification. We measured quantitative parameters representing morphological characteristics of the nonpyramidal cells. Axon collaterals were adequately reconstructed for the quantitative analysis, judging from the total axon length $(18.9 \pm 9.1 \mathrm{~mm} ; 91$ cells $)$, the total number of nodes $(192 \pm 129)$, and the total number of boutons $(3291 \pm 2051)$ (Table 1). Terminal boutons were observed with differential interference contrast. The proportion of bouton in contact with other somata was calculated from 200 randomly sampled boutons. Reconstructed neurons were quantitatively analyzed with NeuroExplorer (MicroBrightField) and the programs that we wrote to obtain the bouton density and

Table 1. Nonpyramidal cells used for the morphological analysis

\begin{tabular}{|c|c|c|c|c|c|c|c|}
\hline Firing & Cell type & Layer & $\begin{array}{l}\text { Number } \\
\text { of cells }\end{array}$ & Chemical marker $^{a}$ & $\begin{array}{l}\text { Total axon } \\
\text { length }(\mathrm{mm})\end{array}$ & Total bouton & Total axon node \\
\hline \multirow[t]{2}{*}{ FS } & FS basket & $\|/\|$ & 18 & & $24.4 \pm 7$ & $3784 \pm 942$ & $234 \pm 87$ \\
\hline & & V & 16 & & $20.4 \pm 5.8$ & $3179 \pm 805$ & $190 \pm 68$ \\
\hline \multirow[t]{3}{*}{ LS } & LS neurogliaform & $\|/\|$ & 7 & & $30.2 \pm 11.5$ & $7287 \pm 3468$ & $376 \pm 224$ \\
\hline & & V & 2 & & $16.6,19.6$ & 1297,3566 & 97,133 \\
\hline & LS basket & II/III & 3 & & $9.2 \pm 1.8$ & $1068 \pm 146$ & $66 \pm 28$ \\
\hline \multirow{5}{*}{ Non-FS } & Non-FS large basket & $\|/\|$ & 11 & CCK (11) & $21.6 \pm 5$ & $3162 \pm 1165$ & $131 \pm 40$ \\
\hline & Non-FS small basket & $\|/\|$ & 7 & $\operatorname{VIP}(3), \operatorname{VIP} / \mathrm{CCK}(2), \mathrm{CRF}(2)$ & $8.6 \pm 3.3$ & $1644 \pm 793$ & $147 \pm 45$ \\
\hline & Non-FS descending basket & $\|/\|$ & 4 & $\operatorname{VIP}(2), \operatorname{CRF}(2)$ & $12.7 \pm 4.7$ & $2268 \pm 953$ & $174 \pm 40$ \\
\hline & Double bouquet & $\|/\|$ & 7 & $\operatorname{VIP}(1), \operatorname{CRF}(2), C R(3), \operatorname{VIP} / C R(1)$ & $8.7 \pm 1.9$ & $1270 \pm 313$ & $117 \pm 20$ \\
\hline & & V & 3 & $\operatorname{VIP}(3)$ & $6.3 \pm 0.7$ & $1078 \pm 291$ & $106 \pm 23$ \\
\hline
\end{tabular}

Data are means \pm SD. SOM, Somatostatin; $C R$, calretinin.

${ }^{a}$ The numbers in parentheses are the number of cells. 
branching angles. The algorithm for measuring curvilinear distances between boutons (interbouton interval) was kindly provided by Dr. L. Tettoni (Lausanne University, Lausanne, Switzerland) (Tettoni et al., 1996, 1998). Curve fitting of the distribution histogram was performed by IGOR Pro. The goodness of curve fitting was evaluated by the square $\left(r^{2}\right)$ of correlation coefficient between the measured values and the calculated ones from the fitting curve.

We measured and computed several categories of morphological parameters. Nodes are branching points of dendrites or axons. Morphometric parameters are: (1) somatic volume (micrometers cubed); (2) number of primary dendrites (dendrites issued from the soma); (3) dendritic and (4) axonal node frequencies (total nodes divided by their total lengths) $(/ 100 \mu \mathrm{m})$; (5) maximum bouton density (mean of five largest bouton numbers within $50 \times 50 \times 50 \mu \mathrm{m}^{3}$ cubes); (6) proportion of boutons apposed to other somata (percentage); and (7) proportion of boutons on the white matter side of their parent cell body (percentage). Each of these parameters is represented by a single value for each cell and used for cell type identification.

The spatial distribution pattern of boutons was represented by vertical and horizontal spread around the parent soma. The vertical spread around the soma was the ratio of boutons outside the $200 \mu \mathrm{m}$ thick horizontal slab centering around the soma to the total boutons. The horizontal spread around soma was the ratio of boutons between 200 and $400 \mu \mathrm{m}$ diameter columns to the total boutons within a $400 \mu \mathrm{m}$ diameter column centering around the soma.

Frequency distributions of values for the following parameters were used for detailed examinations of the axon trajectory, branching, and bouton formation. To calculate branch angles at a node, we drew a straight line from a point on a parent branch just before the node (prenodal point) to the node and from the node to a point on a daughter branch just after the node (postnodal point) (see Fig. 5). Two types of branching angles were measured for each axon node (Burke and Marks, 2002): branching aperture, the angle between daughter branch vectors, and branching tilt, the angle between the parent branch vector and the vector midway between the daughter branch vectors, representing the orientation of the daughter branches at each node. Axon internode intervals are lengths between two successive nodes measured along the axon (including one from the soma origin to the first node). Internode intervals shorter than $500 \mu \mathrm{m}$ (99.97\% of total intervals) were used for the analysis. Direct (linear) distances between successive axon nodes were also measured. Interbouton intervals are curvilinear distances between two successive axon boutons. Interbouton intervals shorter than $100 \mu \mathrm{m}$ (99.98\% of total intervals) was used for the analysis. Frequency histograms of interbouton intervals were extremely skewed, with a peak on the shorter interval and a long tail (Hellwig et al., 1994; Kincaid et al., 1998). Therefore, the interbouton interval is represented by the median for each cell (Amir et al., 1993; Tettoni et al., 1998; Anderson et al., 2002). All these parameters of angles, intervals, and distances were measured in three dimensions.

Frequency histograms of tilt angles and interbouton intervals were fitted by the gamma distribution:

$$
\frac{\beta^{\alpha} x^{\alpha-1}}{\Gamma(\alpha)} e^{-\beta x},
$$

where $\Gamma$ is gamma function, $\alpha$ is shape parameter, and $\beta$ is scale parameter). The shape parameter $(\alpha)$ determines the curve pattern of the distribution including the skew symmetry, but the scale parameter $(\beta)$ only affects the height and broadening of the curve. The exponential distribution:

$$
\frac{1}{\lambda} e^{-\frac{x}{\lambda}}
$$

was fit to the frequency histogram of internode intervals and to the tail of the interbouton interval histogram from its peak. The decay constant $(\lambda)$ was determined from the best fitting exponential. This value $(\lambda)$ would be the mean and the SD of the distribution if axonal branching and bouton formation were a Poisson process. To construct the autocorrelogram of bouton distribution, we extracted one-dimensional lines from the nested axon dendrogram (see Fig. $7 B$ ). The first line was from the most distant ending of the dendrogram back to the branch of the axon origin. The second line was from the second most distant ending back to the longest unused branch. This procedure was repeated as long as the created line was longer than $100 \mu \mathrm{m}$. Calculation of the autocorrelation was started from the boutons on the somatic side toward the distal end for each line. The autocorrelogram of bouton distribution and the $\mathrm{cu}-$ mulative histograms were fitted with a sigmoid function [base $+\max /(1$ $+\exp (($ xhalf $-\mathrm{x}) /$ rate $))$; xhalf is half value].

After reconstruction by Neurolucida, stained cells were serially sectioned using an ultramicrotome. Serial ultra-thin ( $90 \mathrm{~nm}$ thickness) sections were mounted on formvar-coated single slot $(2 \times 1 \mathrm{~mm})$ grids. The thickness of ultra-thin sections was calibrated by a color laser threedimensional profile microscope (VK-9500; Keyence, Osaka, Japan). Electron micrographs were taken at $100 \mathrm{kV}$ with a H-7000 electron microscope (Hitachi), using tilting up to $60^{\circ}$. Electron microscopic images of the labeled terminals and associated structures were captured using a CCD camera and reconstructed (Visilog; Noesis, France).

Statistical analysis. Data are given as the means \pm SD. Statistical analysis was performed using StatView (SAS Institute, Cary, NC). ANOVA was used for confirmation of significant differences among subtypes in individual parameters, followed by post hoc Tukey-HSD (honestly significant difference) test for the group comparison $(\alpha<0.01$ or 0.05$)$. For comparing two cell classes, the Mann-Whitney $U$ test was used ( $p<0.01$ or 0.05 ).

Using the quantified morphological variables, we performed cluster analysis of nonpyramidal cells (Cauli et al., 2000). $R$ (free software; http:// cran.r-project.org/) was used for the cluster analysis. Values are transformed to standard scores by subtraction of the mean and division by SD. The mean and SD of standard scores are 0 and 1, respectively. Each cell was plotted in the multidimensional space of transformed morphological parameters. Every step of the cluster analysis merges two groups (or cells), the combination of which minimizes the variance within each cluster (Ward's method). Clusters are shown in a dendrogram with branch lengths proportional to cluster distance.

\section{Results}

GABAergic nonpyramidal cells in the rat frontal cortex are divided into three groups based on firing characteristics: (1) fastspiking (FS) cells; (2) late-spiking (LS) cells; and (3) non-FS cells (Kawaguchi and Kubota, 1997; Kawaguchi and Kondo, 2002) (supplementary Table 1; available at www.jneurosci.org). First, we quantitatively identified morphological subtypes for each physiological group using morphometric parameters obtained from three-dimensionally reconstructed somata, dendrites, and axons (supplementary Table 2). Subsequently, local axonal characteristics were quantitatively analyzed and compared among morphological types.

\section{Physiological identification of nonpyramidal cells}

FS cells had an abrupt start of nonadapting repetitive discharges at a threshold frequency of $40-150 \mathrm{~Hz}$ in response to current pulses (Fig. 1A). At near-threshold current levels, discharges consisted of either single spike at the beginning of the current pulse or a variable-duration episode of repetitive discharge after a quiescent period, or both. FS cells fired more continuously in response to the depolarizing pulses combined with constant current depolarization than to current pulses with the same total amplitude alone (Fig. 1A2) (Kawaguchi and Kubota, 1998). LS cells were characterized by a slow ramp depolarization at spike threshold (Fig. $1 B$ ). Non-FS cells are more heterogeneous in electrophysiological characteristics than their FS and LS counterparts. The non-FS group contains nonpyramidal cells firing with a decrease in a discharge frequency (accommodation) (regular-spiking nonpyramidal cells) (Fig. 1C1), firing phasically only in the initial portion of a depolarizing current pulse (cells of strong accommodation) (Fig. 1C2), firing spikes more irregularly (cells of irregu- 
lar accommodation) (Fig. 1C3), and firing two or more spikes on slow depolarizing humps (low threshold spikes) from hyperpolarized potentials (burst-spiking nonpyramidal cells) (Fig. 1C4). Ninety-one nonpyramidal cells were physiologically identified and morphologically reconstructed (Table 1).

\section{Synapse formation on axonal boutons}

Axonal boutons are thought to contain synaptic specializations (Kincaid et al., 1998; Shepherd and Harris, 1998; Kubota and Kawaguchi, 2000). We measured the axon size of four types of nonpyramidal cells $(n=5$; two FS cells, one non-FS double bouquet cell, one non-FS Martinotti cell, and one LS neurogliaform cell) (Fig. $1 D$ ) by three-dimensional reconstructions using an electron microscope. Synaptic junctions made by labeled terminals were identified using the following criteria (Buhl et al., 1995): (1) tight apposition of presynaptic and postsynaptic membrane profiles with a widening of the extracellular space and a dense or intermediate plaque of intercellular materials; (2) accumulation of synaptic vesicles in the presynaptic terminal; and (3) postsynaptic density. The serially reconstructed axon terminal with synaptic junctions was not round but ellipsoid (Fig. 1D2,D3). The width and thickness of synaptic boutons $(770 \pm 185 \mathrm{~nm}$ and $469 \pm 152 \mathrm{~nm}$, respectively; $n=152$ ) were much larger than the diameter of intervaricose fibers (Fig. 1D1) $(154 \pm 38 \mathrm{~nm} ; n=144)$. This indicated that axonal boutons with synaptic junction are thicker than other axonal segments and can be used as synaptic contact candidates.

To confirm that the light microscopically identified boutons express synaptic junctions, we consecutively investigated boutons of two FS cells electron microscopically (59 boutons) (Fig. $1 F$ ). Fortysix boutons $(78 \%)$ had the synaptic junction (Fig. 1I) Twelve boutons (20.3\%) had synaptic vesicles, but junctions could not be identified. One bouton only contained a mitochondrion. If the junction plane were oriented almost in parallel with the sectioning direction, the synaptic identification would become difficult, even using tilting of ultra-thin sections. This oversight because of the angle effect would occur more frequently in the case of smaller boutons and junctional areas. In fact, the boutons in which the synaptic junctions were found had larger bouton sectional areas $(0.63 \pm 0.3$ $\left.\mu \mathrm{m}^{2} ; n=46\right)$ at the light microscopic level than those in which the junctions did not $\left(0.44 \pm 0.3 \mu \mathrm{m}^{2} ; n=12\right)$. The angle effect may be one of the reasons for finding boutons only with synaptic vesicles. Most boutons probably express both a synaptic junction and vesicles. This indicated that bouton counts are a good estimate of synapse numbers.
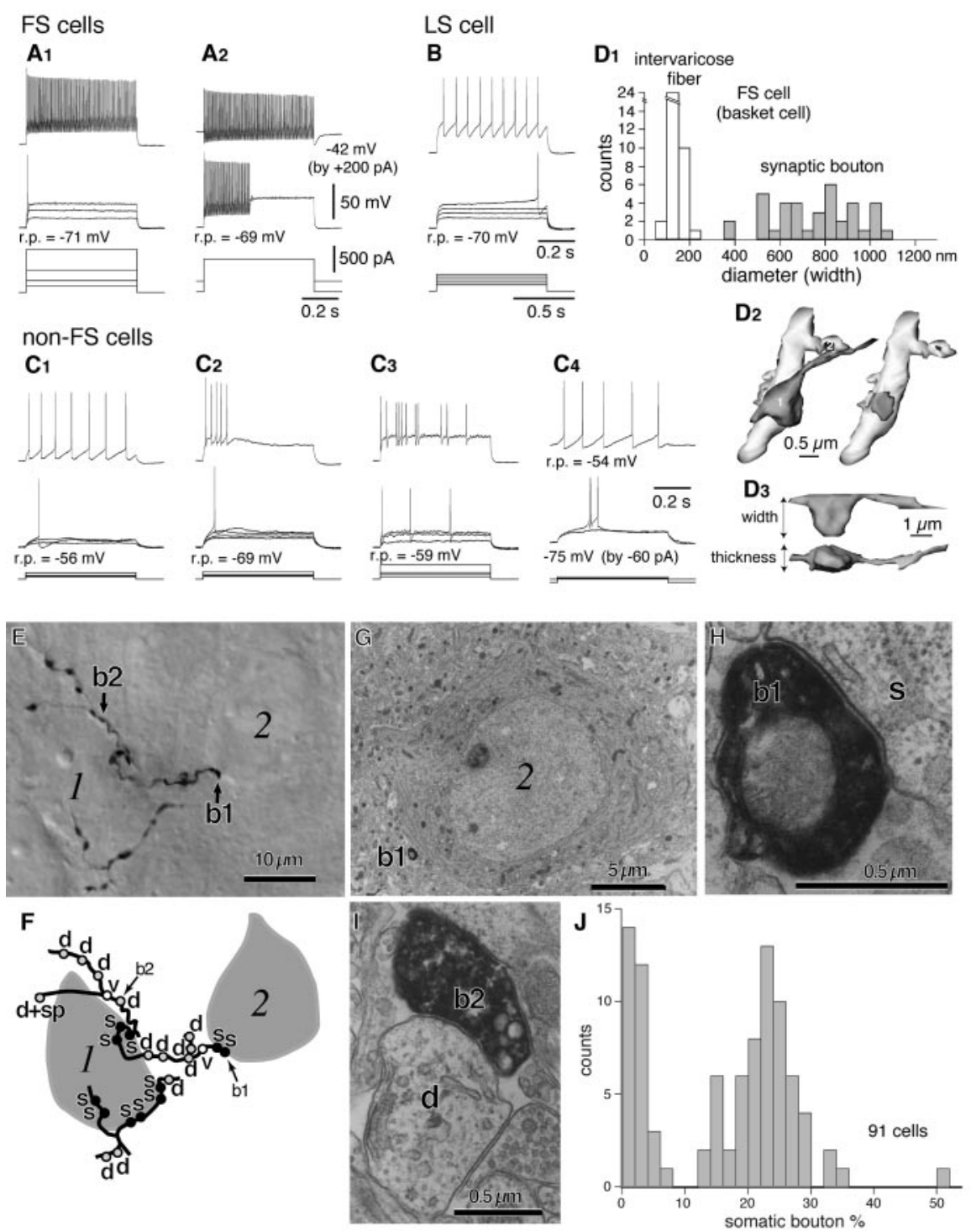

Figure 1. $A-C$, Firing responses of nonpyramidal cells induced by depolarizing currents. r.p., Resting potential. Membrane potentials changed by DC are indicated in parentheses. A1, A2, FS cells. B, A LS cell. C1-C4, Non-FS cells. D1, Distributions of widths of intervaricose axons and synaptic boutons of an FS basket cell. D2, Reconstruction of axon terminals (marked by 1 and 2 ) and the postsynaptic dendrite (pale). The axon terminal 1 from the FS cell made a symmetrical synapse on the shaft. The synaptic junctional areas are shown on the right side. D3, Two views of the FS cell synaptic bouton at right angles. E, Boutons of an FS basket cell and their appositions on unstained somata $(1,2)$ observed with differential interference contrast. $F$, Schematic representation of the axon collaterals and boutons shown in $E$. Identified postsynaptic targets: $s$, soma; $d$, dendritic shaft; $s p$, spine; $d+s p$, a bouton making two synapses on a dendritic shaft and a spine; $v$, synaptic vesicles were observed, but the junction could not be identified. $G$, H, Synaptic contact of the bouton apposition on the soma $(E, b 1)$. s, Soma. I, Dendritic synaptic contact of the identified bouton $(E$, b2). d, Dendrite. J, Distribution of the somatic bouton percentage of nonpyramidal cells. Nonpyramidal cells were divided into cells with a low and high proportion of somatic boutons.

Appositions of DAB-stained axonal boutons on unstained somata were seen by Nomarski optics (Fig. $1 E$ ). We investigated how often these boutons actually made synapses on the somata. Serial ultra-thin sections were made from the axonal arbors of the FS cells displaying somatic appositions. Among boutons apposed to the soma at the light microscopic level, we identified the postsynaptic structures of 89 boutons by an electron microscope. Four-fifths of the synaptic boutons exhibiting somatic contacts at the light microscopic level made a synapse on the soma at the electron microscopic level (Fig. 1G,H) (71 of 89 boutons; $79.8 \%$ ). The remaining made synapses on dendrites and spines of other 


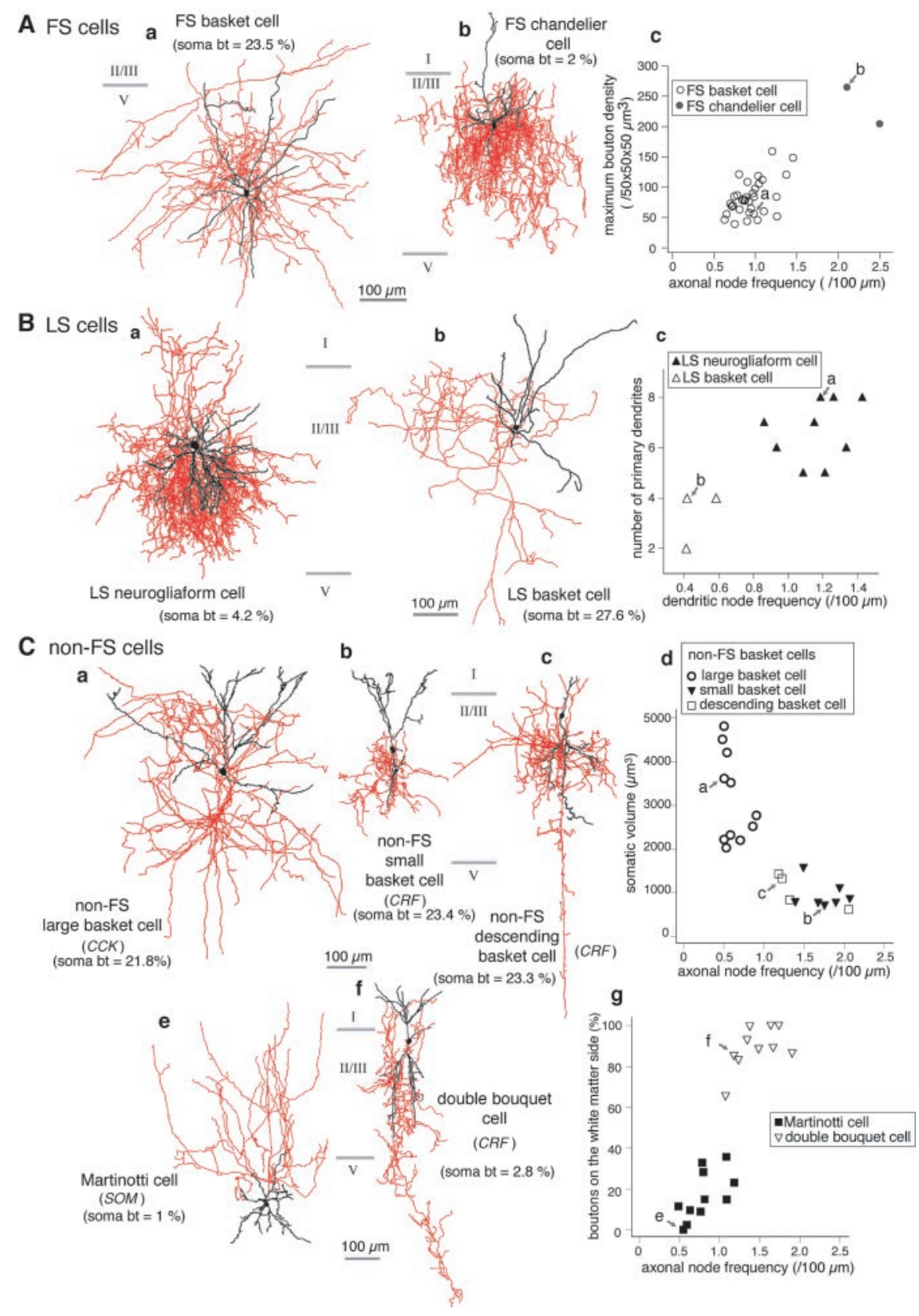

Figure 2. Nonpyramidal cell subtypes. A, FS cell subtypes. $a$, FS basket cell in layer V. b, FS chandelier cell in layer II/III. Roman numerals correspond to the cortical layers. The somata and dendrites are shown in black, and the axons in red. $c$, Distribution of the axonal node frequency and maximum bouton density. soma bt, Somatic bouton percentage. $B$, LS cell subtypes. $a$, LS neurogliaform cell in layer II/III. $b$, LS basket cell in layer II/III. $c$, The number of primary dendrite and the dendritic node frequency. $C$, Non-FS cell subtypes. The identified peptides are shown in parentheses. $a$, Large basket cell. $b$, Small basket cell. $c$, Descending basket cell. $d$, Distribution of the axonal node frequency and somatic volume of non-FS basket cells.e, Martinotti cell. $f$, Double bouquet cell. $g$, The axonal node frequency and proportion of boutons on the white matter side of Martinotti and double bouquet cells.

cells. Because the bouton apposition on somata at the light microscopic level could be used as a somatic synapse indicator, we used the proportion of boutons apposed to other somata for cell classification. This parameter divided nonpyramidal cells into two groups with higher or lower proportion of axosomatic boutons (Fig. $1 \mathrm{~J}$ ). The former included basket cells innervating somata with multiple boutons. Cells with $>12 \%$ axosomatic boutons were defined as basket cells here.

\section{Morphological subtypes of nonpyramidal cells \\ FS cell subtypes}

We found two morphological types of FS cells: basket and chandelier cells (Table 1; Fig. 2A). FS basket cells were defined by axosomatic bouton percentages $>14 \%$ $(22.1 \pm 4.3 \% ; n=34)$. FS basket cells (Fig. $2 \mathrm{Aa}$ ) innervated mostly layers II/III and V but not layer I. Axon collaterals curved toward the horizontal at the border between layers I and II/III and avoided innervating layer I. Two FS cells had characteristic vertical arrays of several axonal boutons innervating axon initial segments (Fig. 2Ab) and were defined as chandelier cells (Szentágothai, 1975; Somogyi, 1977; Somogyi et al., 1982; Kawaguchi and Kubota, 1998). Chandelier cells had somatic bouton percentages $<5 \%$ ( 2 and $2.3 \%$ ). The maximum bouton density and axonal node frequency of chandelier cells were higher than those of FS basket cells (Fig. 2Ac).

\section{LS cell subtypes}

Two morphological types of LS cells were found in the sample: neurogliaform and basket cells (Table 1). LS basket cells (Fig. $2 \mathrm{Bb}$ ) were defined by axosomatic bouton percentages $(26.7 \pm 3.4 \%)$ larger than the others $(6 \pm 5.8 \%)$. Neurogliaform cells (Fig. $2 \mathrm{Ba}$ ) were identified by a larger number of primary dendrites and a higher frequency of dendritic nodes than LS basket cells $(p<0.05)$ (Fig. 2 Bc). LS neurogliaform cells had a dendritic field of $100-$ $200 \mu \mathrm{m}$ and an axonal arbor twice as wide as that of their dendritic field (Jones, 1984a; Kawaguchi, 1995). The axon collaterals running horizontally turned at the horizontal edge of the axon territory (Kawaguchi, 1995). Neurogliaform cells were higher in maximum bouton density than LS basket cells ( $p<$ $0.05)$. One LS cell in layer $\mathrm{V}$ was similar in dendritic morphology to the other neurogliaform cells, but its local innervation was sparser (see Fig. 9A1, asterisk). This cell was included in the neurogliaform type here but excluded from the group comparisons. Input resistances and membrane time constants of LS neurogliaform cells were smaller than those of LS basket cells $(p<0.05)$.

Non-FS cell subtypes

Non-FS cells were divided into basket cells (proportion of somatic boutons, $>12 \% ; 24.8 \pm 7.7 \%, n=22)$ and others $(<7 \%$; $1.9 \pm 1.7 \%, n=21$ ) (Table 1). Non-FS basket cells were further classified into three subclasses by their somatic size, axon branching pattern, and axon elongation pattern (Fig. 2C): (1) large basket cells $(n=11)$; (2) small basket cells $(n=7)$; and (3) descending basket cells $(n=4)$. Large basket cells (Fig. $2 \mathrm{Ca}$ ) had larger 
somatic volumes and lower frequency of axon nodes than other basket cells $(\alpha<$ 0.01) (Fig. 2Cd). Compared with small basket cells (Fig. 2Cb), descending basket cells (Fig. 2Cc) had descending axons with collaterals bearing multiple boutons on other cell bodies.

Non-FS cells other than basket cells include Martinotti cells with axonal arbors ascending to layer I (Fig. 2Ce) $(n=11)$ and double bouquet cells with narrow descending arbors (Fig. 2Cf) $(n=10)$. Martinotti cells were lower in axonal node frequency than double bouquet cells ( $\alpha<$ 0.01 ) (Fig. 2Cg). Martinotti cells (17 \pm $12 \%$ ) were lower in proportion of boutons on the white matter side of the soma than double bouquet ( $89 \pm 10 \%$ ) (Fig. $2 C g$ ), large basket $(73 \pm 14 \%)$, small basket $(88 \pm 11 \%)$, and descending basket $(92 \pm$ $2 \%)$ cells $(\alpha<0.01)$.

To corroborate the validity of the morphological classification of non-FS cells, we investigated whether the morphological groups identified above correspond to the cell classes identified by the immunohistochemical expression patterns. The cluster analysis used a set of four morphological parameters (the somatic bouton percentage, somatic volume, axonal node frequency, and proportion of boutons on the white matter side) and revealed four major morphological clusters (Fig. 3A), which corresponded to the previously described types: (1) Martinotti cells; (2) large basket cells; (3) small/descending basket cells; and (4) double bouquet cells. Martinotti and large basket cells were immunoreactive for somatostatin and CCK, respectively. Small/descending basket and double bouquet cells were positive for VIP, CRF, CCK, or calretinin (Table 1). Two small basket cells were positive for CCK, but they were also positive for VIP. The expression pattern of these peptides and calretinin on morphological clusters was correlated with immunohistochemical classification of GABA cells in the rat frontal cortex reported previously (Fig. 3B) (Kawaguchi and Kubota, 1997; Kubota and Kawaguchi, 1997): (1) somatostatin cells are mostly separate from cells positive for calretinin, VIP or CCK; (2) CCK cells are divided into two subpopulations positive or negative for both VIP and CRF; (3) Most CRF cells belong to the VIP cell group, but a few CRF cells in layer V/VI are positive for somatostatin and belong to its minor population (Demeulemeester et al., 1988) (Y. Kubota and Y. Kawaguchi, unpublished observations).

\section{Bouton spatial distribution of nonpyramidal cell subtypes}

We identified nine subtypes among 91 nonpyramidal cells in this study (Table 1): (1) FS basket; (2) FS chandelier; (3) LS neurogliaform; (4) LS basket; (5) non-FS large basket; (6) non-FS small basket; (7) non-FS descending basket; (8) Martinotti; and (9) double bouquet. Because these cells were different in their innervation field, the spatial distribution pattern of boutons was quan-
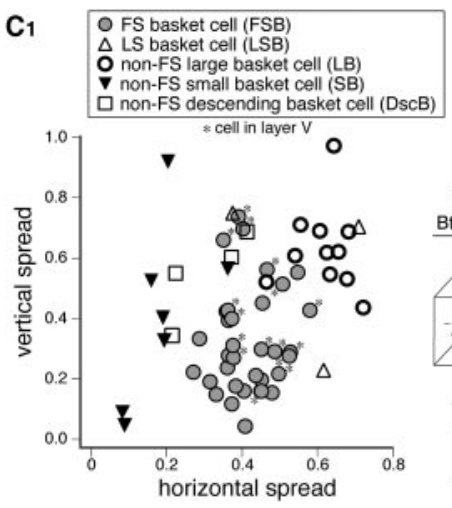

Vertical spread: Bt. outside $200 \mu \mathrm{m}$ slab total Bt.
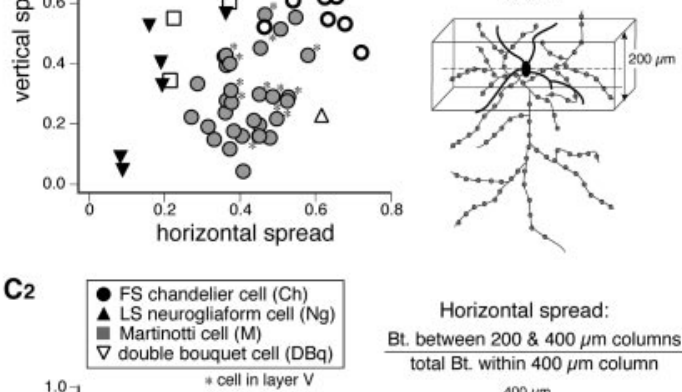

Horizontal spread Bt. between $200 \& 400 \mu \mathrm{m}$ columns total Bt. within $400 \mu \mathrm{m}$ column
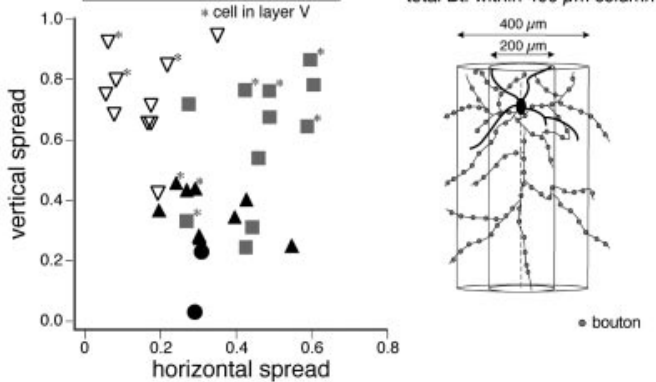

horizontal spread

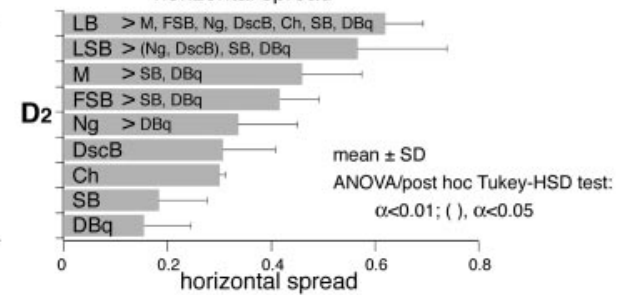

Figure 3. A, Cluster analysis of non-FS cells using the somatic bouton percentage, somatic volume, axonal node frequency, and proportion of boutons on the white matter side. Ordinate, individual cells labeled with positive immunohistochemical markers; (

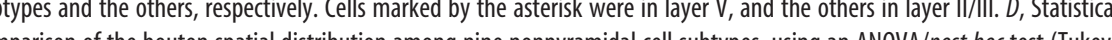
comparison of the bouton spatial distribution among nine nonpyramidal cell subtypes, using an ANOVA/post hoc test (TukeyHSD). Cell types are ranked in descending order of the mean for individual parameters. D1, Vertical spreads. D2, Horizontal spreads.

tified and compared between them. The bouton distribution pattern was quantified by the vertical and horizontal spread around the soma (Fig. 3C). Each subtype had a characteristic combination of the horizontal and vertical spread around the somata, although these two parameters related to the bouton spatial distribution were not used for the classification. The bouton field of non-FS large basket cells was vertically and horizontally more diffuse than that of FS basket cells $(\alpha<0.01)$ (Fig. 3C1,D). The fields of non-FS small basket cells were horizontally more compact than those of large and FS basket cells $(\alpha<0.01)$ (Fig. $3 C 1, D)$. The LS basket cells were variable in the axonal field. The field of FS basket cells in layer II/III were more compact than that of layer $\mathrm{V}$ cells $(p<0.05)$. Among the other types than basket cells, double bouquet cells were horizontally more compact in the field $(\alpha<0.01)$ (Fig. 3C2,D).

\section{Axon branching phenotypes}

The axon branching pattern is determined by the internode course, internode interval, and branching angles at the node. 


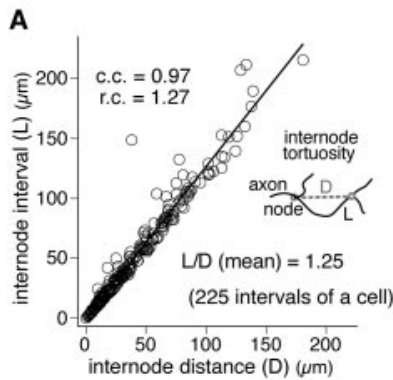

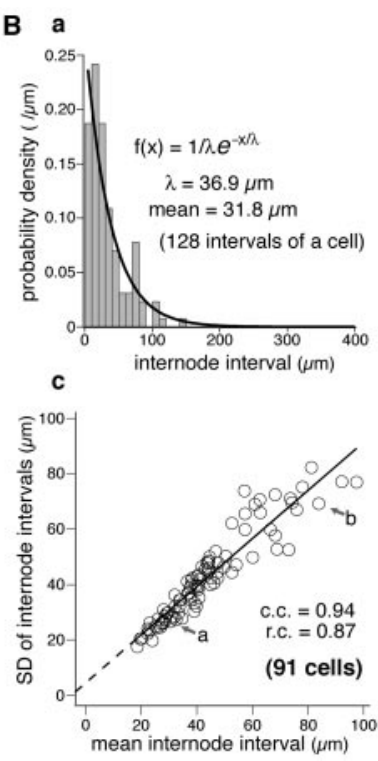

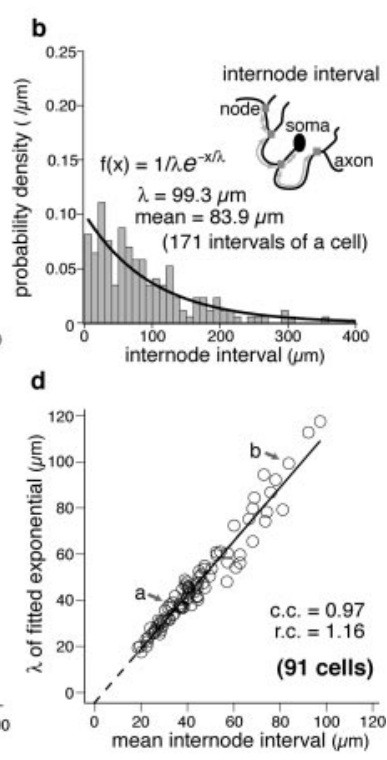

Figure 4. $A$, Linear relationship of internode direct distances and intervals of a single cell (large basket cell). Solid line, Simple regression fit. Tortuosity, ratio of the internode interval $(\mathrm{L})$ to the direct distance (D). $B$, Axon internode interval. $a, b$, Frequency distributions of internode intervals of two cells with shorter and longer means (small and large basket cells, respectively). Thick line, Fitted exponential distribution; $\lambda$, decay constant of the fitted exponential ( $x$, interval). $c$, Linear relationship of the SD and mean of internode intervals of all cells. a and b correspond to cells shown in $a$ and $b$, respectively. Solid line, Simple regression fit; c.c., correlation coefficient; r.c., regression coefficient. $d$, Linear relationship of the decay constant $(\lambda)$ and the mean of internode intervals.

Table 2. Curve-fitting goodness of parameter distributions

\begin{tabular}{llr}
\hline Parameter & Curve fitting & \multicolumn{1}{c}{$r^{2}$} \\
\hline Internode interval & Exponential & $0.9 \pm 0.083$ \\
Aperture angles & Gaussian & $0.827 \pm 0.106$ \\
Tilt angles & Gamma (shape p. $=2.17 \pm 0.16)$ & $0.8 \pm 0.134$ \\
Vertical direction change & Gaussian & $0.909 \pm 0.049$ \\
Interbouton interval & Gamma (shape p. $=2.02 \pm 0.18)$ & $0.976 \pm 0.017$ \\
& Exponential (from the peak) & $0.984 \pm 0.01$ \\
\hline
\end{tabular}

Data are means \pm SD $(n=91)$. shape $p$. Shape parameter of gamma distribution.

$r^{2}$, Square of correlation coefficient between the measured values and the calculated ones from the fitting curve.

These branching characteristics were quantified in several parameters.

How does the axon proceed between nodes?

To quantify how the axon branch meanders, we measured both the internode interval (length along the axon) and the direct (linear) internode distance. Internode intervals linearly increased with the internode direct distance irrespective of cell types (Fig. $4 A$ ) (correlation coefficient, $0.971 \pm 0.033 ; 12$ cells). The ratio of the internode interval to the direct distance (internode tortuosity) was mostly between 1.1 and 1.3 (1.25 \pm 0.07 ; means of 91 cells; range, 1.128-1.445). The tortuosity of the FS basket cell was smaller than the small basket, double bouquet $(\alpha<0.01)$ (see Fig. $8 A$ ), neurogliaform, and Martinotti $(\alpha<0.05)$ cells (see Fig. $8 A$ ). FS basket cells in layer $\mathrm{V}(1.18 \pm 0.03)$ were smaller in tortuosity than those in layer II/III $(1.23 \pm 0.06)(p<0.05)$. The other pairs were not significantly different. These indicate that axon branch meandering is independent of the branch length and not different among most subtypes.

Where does the axon make branches?

The frequency histogram of axon internode intervals was positively skewed (Kisvárday et al., 1985) and followed an exponential distribution for each cell (Fig. $4 B a, b$; Table 2). For an exponential distribution, the mean equals the SD. In fact, the slope of the regression line of SDs and means of 91 cells was close to 1 , and the intersection of the line at the axis of mean $(\mathrm{SD}=0)$ was close to zero (Fig. $4 \mathrm{Bc}$ ). The decay constants calculated from the fitted exponential correlated with the interval means of 91 cells (Fig. $4 B d$ ). Internode intervals would distribute exponentially if branching was a Poisson process. These data indicate that axon branching indeed occurs according to a Poisson process, and the mean interval varies among nonpyramidal cells $(20-100 \mu \mathrm{m})$ (see Fig. $8 B$ ).

\section{How does the parent axon branch divide into two daughters?}

We measured two angles at each node, determining the orientation of the daughter branches (Fig. 5A). The aperture angle observed a Gaussian distribution for each cell $\left(86.9 \pm 4.6^{\circ}\right.$; means of 91 cells; average of SDs, $33.8^{\circ}$ ) (Table 2). The tilt angle $\left(66.2 \pm 10.7^{\circ}\right.$; means of 91 cells; average of SDs, $37.3^{\circ}$ ) could be fitted with a gamma distribution for each cell (peak location, $\left.40.9 \pm 10.2^{\circ}\right)($ Table 2$)$. Branching angle distribution patterns were similar among subtypes (Table 2; Fig. $5 C)$. Aperture angles of neurogliaform cells were smaller than some subtypes ( $\alpha<0.01$ or 0.05 ) (see Fig. $8 C$ ). Tilt angles of large basket cells were smaller than descending basket, Martinotti, and FS basket cells $(\alpha<0.01)$ (Fig. $8 D)$. Because the aperture and tilt angles were similar between most subtypes, it is supposed that the manner of generating daughter branches at the node is common among nonpyramidal cells and that the daughter branches do not continue in the direction of the parent branch but bend from the parent at $\sim 40^{\circ}$.

How does the axon choose the heading course?

We investigated the vertical direction change at the node by measuring the angle differences between the parent and daughter axons with reference to the horizontal (Fig. 5B). The angle difference took the Gaussian distribution for each cell $\left(1.4 \pm 5.2^{\circ}\right.$; means of 91 cells; average of SDs, $48.9^{\circ}$ ) (Table 2) and was similar in distribution among subtypes (not significantly different among subtypes; ANOVA) (Fig. 5C). Although Martinotti and double bouquet cells distinctly differ in the vertical direction of innervation, the distributions of angle differences at the node were very similar between them and independent of the preferred directions. Innervation directions seemed to be mostly determined by the trajectory between axon nodes. In fact, the axon collaterals, especially close to the somatic origin, exhibited the path characteristic of each subtype. Some somatostatin Martinotti cells issued main axons from the white matter side of the somata or of their horizontal or descending dendrites, but the axons shortly changed direction and generated ascending branches (Fig. 5D). Similarly, the main axons of some cells with descending axonal arbors originated from the pia side of the somata, or from horizontal or ascending dendrites, but soon changed direction toward the white matter. 
Synaptic bouton phenotypes

How do synaptic boutons distribute on the axonal arbor?

The bouton density may change along the axon, depending on intracortical location differences such as the layer, cortical depth, or distance from the soma. We compared the bouton distributions along the axon between different internode intervals. Boutons increased in number linearly with the interval length (Fig. 6A) (correlation coefficient, $0.906 \pm 0.08 ; n=$ 6: two FS basket, two Martinotti, and two double bouquet cells). We also compared the bouton distributions along the axon between zones at different distances from the soma. The axonal tree was divided by two concentric spheres centered on the soma into three regions, each containing one-third of the total axon (Fig. $6 \mathrm{~B}$ ). Bouton densities in the all three regions were very similar in most cells (Fig. $6 \mathrm{~B}$ ) (bouton ratio of far to near region, $1.01 \pm 0.14 ; 91$ cells). These observations revealed that the boutons distributed homogeneously along the whole axon independent of the internode interval length and the distance from the soma.

\section{Where does the axon make synaptic} boutons and junctions?

Because the boutons of nonpyramidal cells distributed homogeneously along the axon, it should be revealed whether the bouton distribution along the axon was more regular or random and whether the distribution pattern was dependent on the subtype or not. The frequency histogram of interbouton intervals was characteristically skewed in all cells with a long tail at long intervals and a low incidence at short intervals (Fig. $6 \mathrm{Ca}, \mathrm{Cb}$ ) (Hellwig et al., 1994; Tettoni et al., 1998). It could be well fitted by the gamma distribution for each cell (peak location, $3.1 \pm 0.8$ $\mu \mathrm{m}$ ) (Table 2). The regression line between the mean and SD of the intervals (correlation coefficient, 0.92) had the slope of 1.05. (Fig. $6 C c$ ). The intersection at $\mathrm{SD}=0$ was not zero $(0.99$ $\mu \mathrm{m})$. These suggest that the interbouton intervals observe a Poisson process with a constraint of a low incidence of very small intervals (Anderson et al., 2002; Shepherd et al., 2002). Indeed, The tail of the distributions was fitted well to the exponential distribution (Fig. $6 \mathrm{Ca}, \mathrm{Cb}$; Table 2). The decay constants calculated from the fitted exponential varied among cells and correlated well with the medians of the interbouton intervals $(3-10 \mu \mathrm{m})$ (Fig. 6Cd).

To confirm the low probability of very short interbouton intervals and the homogeneous bouton density at longer intervals, we compared the autocorrelation of the bouton distributions of three Martinotti, three FS basket, and two FS chandelier cells (Fig. $7 A, B)$. Except for the initial part of the autocorrelogram, the bouton density was constant and almost identical for respective subtypes $(0.23 \pm 0.02 / \mu \mathrm{m}$ from 10 to $100 \mu \mathrm{m}$ for Martinotti cells; $0.16 \pm 0.02 / \mu \mathrm{m}$ for FS basket cells; 0.25 and $0.26 / \mu \mathrm{m}$ for chandelier cells). The initial part of the autocorrelogram was fitted by the sigmoid curve and was similar among cells (Fig. 7A) (half value, $1.28 \pm 0.52 \mu \mathrm{m}$ for Martinotti cells; $1.56 \pm 0.75 \mu \mathrm{m}$ for FS basket cells; and 0.81 and $0.86 \mu \mathrm{m}$ for chandelier cells).

The reduced bouton distribution at short distances in the autocorrelogram was thought to be attributable to the finite length of the bouton. We measured the bouton length along the axon $(1166 \pm 389 \mathrm{~nm})$ by reconstructing 230 synaptic boutons of seven nonpyramidal cells (two FS, one Martinotti, three double bouquet, and one neurogliaform cells) from serial ultra-thin sections (Fig. 7C). The cumulative histogram of the bouton length was fitted with the sigmoid function. The half value of the sigmoid fit for the bouton length $(1.06 \mu \mathrm{m})$ was similar to those for the autocorrelograms of bouton distributions. Thus, synaptic boutons distributed homogeneously with random intervals constrained by the bouton length (Fig. $7 F$ ).

One possible way to innervate two targets within the bouton length is a two-junction formation on a single bouton. We investigated how often the axon creates boutons with two junctions by examining the 230 synaptic boutons (Fig. $7 D$ ). The postsynaptic structures of the synaptic boutons were somata $(n=20)$, dendritic shafts $(n=147)$, and spines $(n=74)$. Eleven boutons $(4.8 \%)$ had two junctions [ $2 \%$ for two FS cells ( $n=49$ boutons), $6.9 \%$ for a Martinotti cell $(n=29), 5.8 \%$ for three double bouquet cells $(n=121)$, and $3.2 \%$ for a neurogliaform cell $(n=31)]$. Two-junction boutons were found in each class, but its proportion might be different among subtypes. Boutons with two junctions were divided into two patterns: junctions on the same side $(n=7)$ (Fig. 7D2) and junctions on opposite sides $(n=4)$ (Fig. 
A

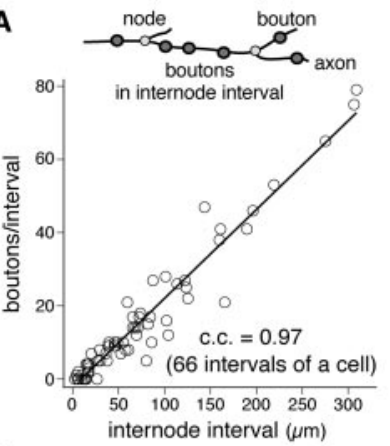

C a
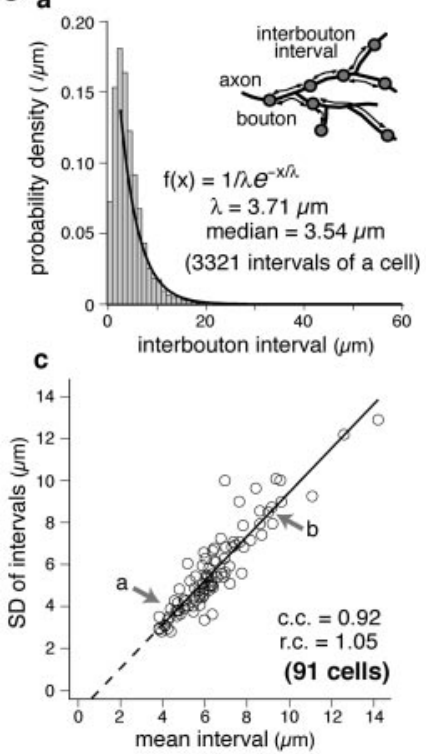

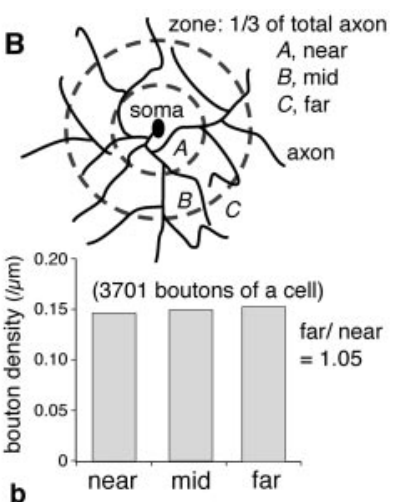

b
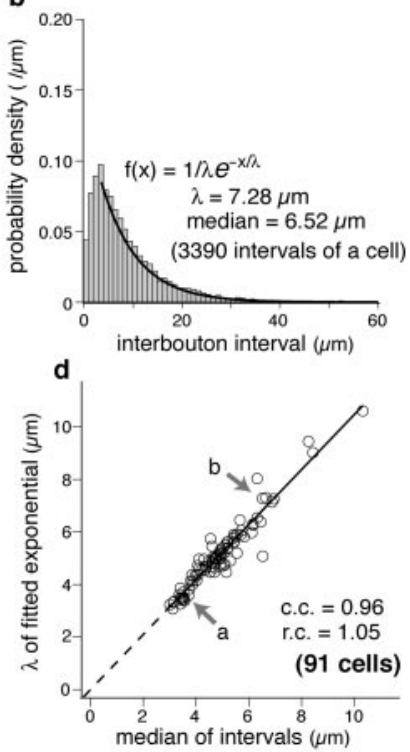

Figure 6. Synaptic bouton distributions along the axon. $A$, Linear relationship of the bouton number and internode interval of a single cell (Martinotti cell). Solid line, Simple regression fit; C.C., correlation coefficient. $B$, Ratio of boutons in the far region to those in the near near one, suggesting the homogeneous distribution along the axon independent of the distance from the soma. Near region, The sphere containing one-third of the total axon length; far region, outside the sphere containing the two-thirds. C, Axon interbouton interval. $a, b$, Frequency histograms of the interbouton intervals of two cells with shorter and longer medians (Martinotti and FS basket cells, respectively). Thick line, Fitted exponential distribution from the peak. c, Linear relationship of the SD and mean of interbouton intervals. $a$ and $b$ correspond to cells shown in a and $b$, respectively. Solid line, Simple regression fit; r.c., regression coefficient. $d$, Linear relationship of the decay constant $(\lambda)$ and the median of interbouton intervals.

7D3) of the bouton. The postsynaptic structures of the two junction boutons were dendritic shafts or spines. Most paired junctions within one bouton (10 of 11) innervated the different targets but not the continuous surface of the same target. We compared the two-junction boutons to a subset of two successive boutons with single junctions $(n=38)$ (Fig. 7D1). Respective junction areas were similar between single and two-junction boutons $\left[0.17 \pm 0.11 \mu \mathrm{m}^{2}\right.$ ( $n=38$ junctions) for single junction boutons; $0.14 \pm 0.07 \mu \mathrm{m}^{2}$ ( $n=22$ junctions) for two-junction boutons]. Interjunction distances were $0.73 \pm 0.28 \mu \mathrm{m}$ in two-junction boutons (Fig. $7 E$ ). Thus, axons can innervate two different targets separated by a distance smaller than the bouton length, by making two synaptic junctions on a single bouton (Fig. $7 F$ ).

To determine the spatial pattern of boutons made by an axon on a single target, we measured successive bouton intervals of basket cells on the same somata (Fig. 7G): five FS basket (3.8 $1.7 \mu \mathrm{m}$; range, $0.9-9.1 \mu \mathrm{m} ; n=92$ intervals), two large basket (4.4 $\pm 2.6 \mu \mathrm{m}$; range, $1.2-15 \mu \mathrm{m} ; n=49)$, two small basket
(3.7 $\pm 2.2 \mu \mathrm{m}$; range, $0.8-13.3 \mu \mathrm{m} ; n=37$ ), and two descending basket ( $4.3 \pm 2 \mu \mathrm{m}$; range, $1.3-11.6 \mu \mathrm{m} ; n=44)$ cells. This suggests that interbouton intervals of basket terminals on the same somata included longer ones and were not so regular. Chandelier cells are known to make several consecutive synapses on the same initial segments (Somogyi et al., 1982). The bouton position autocorrelograms (two chandelier cells) (Fig. 7H), however, were homogeneous, except the initial distances like those of other subtypes (Fig. 7A). This may suggest a certain degree of irregularity in bouton formation, even on the same continuous target.

\section{Specific morphological characteristics for the nonpyramidal cell subtype}

Nonpyramidal cells exhibited similar axonal tortuosity and branching angles among most subtypes (Fig. $8 A, C, D$ ). Although internode and interbouton intervals could be fitted by the same forms of probability density function, respectively (Table 2), their averages were more different among cells (Fig. $8 B, E$ ). We, therefore, examined the relationship between the internode interval means and the interbouton interval medians (Fig. 9A, $B$ ).

First, the two factors were compared for FS cells and LS neurogliaform cells (Fig. 9A1). FS chandelier cells showed shorter node and bouton intervals than FS basket cells. LS neurogliaform cells, except one cell (Fig. 9A1, asterisk), were longer in the node interval than FS chandelier cells and shorter in the bouton interval than FS basket cells $(\alpha<0.01)$. One neurogliaform cell with sparse boutons (Fig. 9A1, asterisk) showed longer bouton intervals than other LS neurogliaform cells and FS cells. Interbouton interval medians and internode interval means of FS basket cells were not significantly different between layer II/III and layer V.

Comparing non-FS non-basket cells, Martinotti and double bouquet cells (Fig. 9A2), Martinotti cells were longer in the node interval than double bouquet cells $(\alpha<0.01)$ and shorter in the bouton interval, although not significant by the post hoc test. Interbouton interval medians and internode interval means of Martinotti cells were shorter in layer II/III than layer V, although the differences were not significant. Compared with FS cells, Martinotti cells were shorter in the bouton interval than FS basket cells $(\alpha<0.01)$.

Among basket cells, large basket cells were larger in the internode interval than FS, small and descending ones $(\alpha<0.01)$ (Fig. $9 A 1, A 3)$. Large basket cells are larger in the interbouton interval than small basket cells $(\alpha<0.01)$ (Fig. 9A3). Small and descending basket cells were shorter in the node interval than non-FS large basket cells $(\alpha<0.01)$ (Fig. 9A3). These results show that nonpyramidal cell subtypes show a characteristic combination of the internode and interbouton interval averages (Fig. 9C).

Because each subtype had a characteristic combination of averaged parameter values in both the bouton spatial distribution (the horizontal and vertical spread around somata) and the local axon phenotypes (interbouton interval median and internode interval mean), we compared these four parameters together. This plot revealed a characteristic association of four parameters in each subtype and the similarity between layer II/III and V cells (Fig. 9D).

\section{Discussion}

Because neuronal wiring is achieved by axonal outgrowth, branching, and synapse formation, we studied these morphological characteristics quantitatively in nonpyramidal cell subtypes. Morphological subtypes within each physiological class were identified mostly on the basis of (1) proportion of somatic bou- 
ton contacts, (2) axon branching frequency, and (3) proportion of boutons on the white matter side of the soma. Each morphological subtype showed a characteristic spatial distribution of boutons around the somata. Each parameter of local phenotypes followed its own characteristic distribution pattern, which was fitted to a particular probability density function irrespective of subtypes. The possible fitting to a certain function could suggest the background rules of branching and bouton formation. The aperture angles and vertical direction changes at the node followed a Gaussian distribution, whereas the tilt angles followed a gamma distribution; the peak values of these parameters were not so different among most subtypes. The internode and interbouton intervals were mostly fitted with the exponential with decay constants that varied among subtypes. Each subtype showed a distinct combination of internode and interbouton interval averages. The subtype-specific association of morphological parameter values related to the node and bouton distributions along the axon as well as bouton spatial distributions revealed the distinctive innervation characteristics of each subtype (Fig. 3C, 9).

\section{Local axon phenotypes in \\ nonpyramidal cells}

Axon proceeding among the targets

The internode tortuosity was similar among most subtypes. Because the internode tortuosity was $\sim 1.25$, most axons do not seem to meander very much between branch points. If the axon actively searched its specific targets, the tortuosity would be expected to vary among subtypes with different target selectivities. The GABAergic axon might, therefore, make synapses at the point of encounter with specific targets while proceeding in a relatively straight course.

\section{Determinants of axon course direction}

The vertical direction changes at nodes were similar among different subtypes. The mean angle change was $\sim 0^{\circ}$; as a result, the vertical directions of daughter branches did not deviate, overall, from that of the parent. Changes in the direction of axonal growth seem to occur mostly between nodes (internode trajectory).

\section{Branching characteristics}

Because the frequency histogram of internode intervals could be fitted to an exponential, branching seems to occur randomly, with a mean internode interval typical of each subtype. The distribution of tilt angles was skewed by reduced probability around zero degree. This indicates that axons do not go straight but bend at the node. The tilted daughter branches induce the increase of
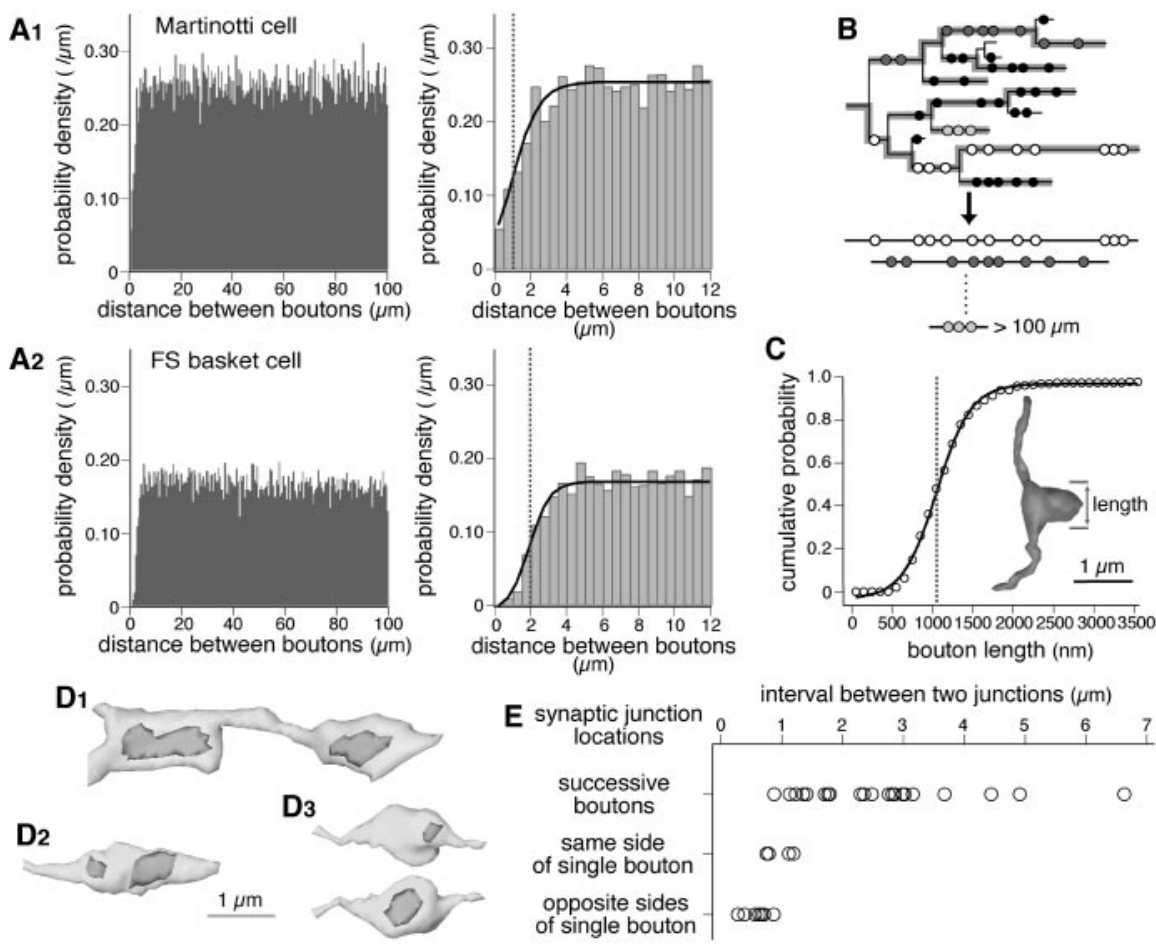

E synaptic junction

interval between two junctions $(\mu \mathrm{m})$
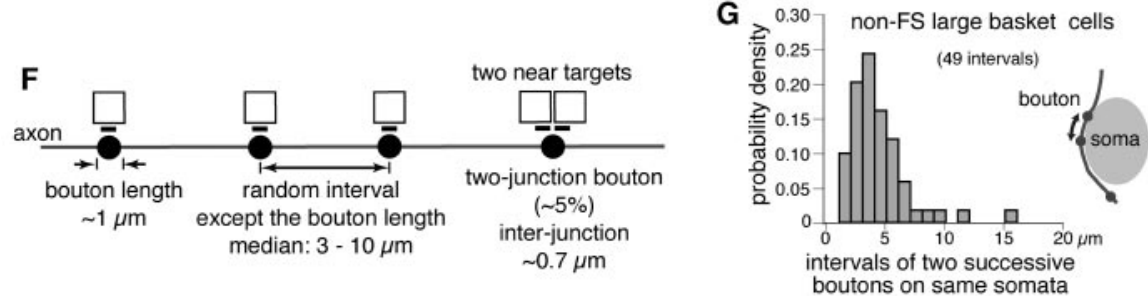

\section{synaptic target \\ - synaptic junction \\ synaptic bouton}

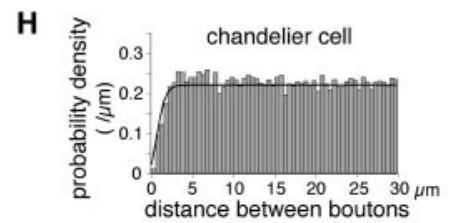

Figure 7. $A 1, A 2$, Autocorrelograms of bouton arrangements along the axons of Martinotti (1401 boutons) and FS basket cells (1878 boutons). Right, Enlargements to $12 \mu \mathrm{m}$. Thick line, Fitted sigmoid function; dotted line, half value of sigmoid function. Bin, $0.5 \mu \mathrm{m}$. $B$, The way to construct one-dimensional bouton lines from the nested axon dendrogram for calculating the autocorrelogram. C, The cumulative histogram of the bouton length along the axon of 230 boutons reconstructed from serial ultra-thin sections of seven nonpyramidal cells. Thick line, Fitted sigmoid function; dotted line, half value of sigmoid function. Bin, $0.1 \mu \mathrm{m}$. $D$, Three types of axonal boutons different in junction number and intrabouton location. D1, Boutons with a single junction area. Two successive boutons were reconstructed. D2, A bouton with two junction areas on the same side. D3, A bouton with two junction areas on the opposite sides. Two views of the bouton with $180^{\circ}$ rotation are shown. $E$, Intervals between synaptic junction centers in three types of successive junction relationships. F, Schematic view of the synaptic bouton arrangement of nonpyramidal cells. $G$, Frequency distribution of the intervals of two successive boutons on the same somata, obtained from two large basket cells. $H$, The autocorrelogram of bouton arrangements along the axons of an FS chandelier cell (2049 boutons).

axonal plexus density locally. Neurogliaform cells had the smaller aperture angles that may cause denser local innervation. Non-FS large basket cells had the smaller tilt angles that may be related wider innervation.

\section{Synaptic bouton formation}

The reduced distribution of bouton intervals at short distances was thought to be attributable to the finite length of bouton itself. As a complement mechanism innervating two targets within the bouton length, synaptic boutons could make two junctions on separate targets at short distances (mean, $\sim 0.7 \mu \mathrm{m}$ ) (Fig. $7 E$ ). This indicates that synaptic junction formation may be depen- 

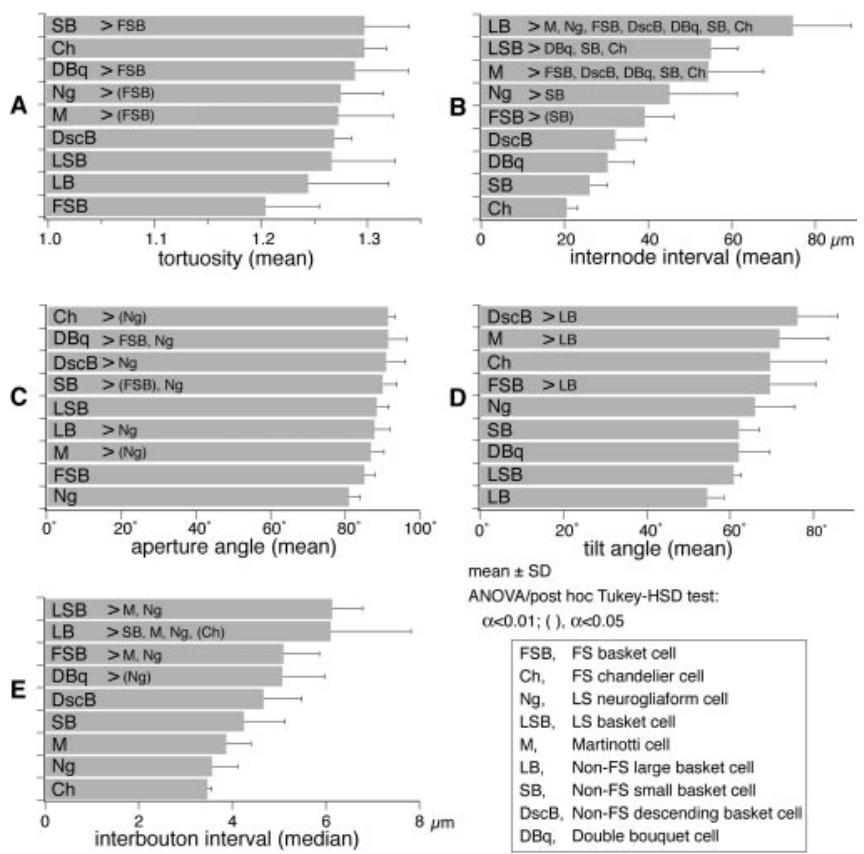

Figure 8. Statistical comparison of the axon local characteristics among nine nonpyramidal cell subtypes, using an ANOVA/post hoc test (Tukey-HSD). Cell types are ranked in descending order of the mean for individual parameters. $A$, Means of tortuosity. $B$, Means of the internode interval. C, Means of aperture angle. $D$, Means of tilt angle. $E$, Medians of interbouton interval.

dent on the spatial distribution pattern of targets. Because two junctions could exist within the bouton length, interjunction intervals were thought to be shorter in mean than interbouton intervals, and their frequency distribution would be fitted to the exponential even at short intervals.

\section{Random occurrence of synaptic boutons along the axon}

Considering the domain selectivity of cortical GABA cell innervation, the homogeneous distribution and random placement of synaptic junctions suggest random spacing of the target structures within the cortex (Anderson et al., 2002). The random and nonclustered distribution has been reported in VIP-positive interneurons in the superficial layers of the rat visual cortex (Morrison et al., 1984) and Meynert cells of the projection type in layer V/VI of the monkey visual cortex (Winfield et al., 1981). However, it remains undetermined how the specific postsynaptic structures spatially distribute within the cortex.

Interbouton intervals of two successive boutons on the same somata were not necessarily regular and included longer ones. Chandelier cells, axo-axonic cells, make several consecutive synapses on the same initial segments (Somogyi, 1977; Freund et al., 1983; Peters, 1984). In the cat visual cortex, one axo-axonic cell makes eight synapses, on average, on one initial segment (Somogyi et al., 1982). Their interbouton interval distributions, however, were fitted to the exponential, and the bouton-position autocorrelogram took a uniform pattern. The irregularity in bouton formation even on the same continuous target may suggest the irregular bouton formation tendency inherent to the presynaptic axons, or else the postsynaptic influence such as differences in activity and cell type. In addition to the spatial distribution of specific targets, the different influences from individual targets and the presynaptic inherent irregularity may contribute to the apparent randomness of bouton arrangement.

\section{Subtype characteristics of nonpyramidal cells}

We quantitatively identified the following main classes using several morphometric parameters: (1) basket cells; (2) chandelier cells; (3) neurogliaform cells; (4) Martinotti cells; and (5) double bouquet cells. Some GABAergic subtypes described previously were not included in this study: FS non-basket (dendritetargeting) cells (Kawaguchi and Kubota, 1998); somatostatin wide arbor cells (Kawaguchi and Kubota, 1998); VIP arcade cells forming basket terminals (Kawaguchi and Kubota, 1996); VIP horizontal arbor cells (Kawaguchi and Kubota, 1996); and non-FS chandelier cells (Kawaguchi, 1995).

\section{Basket cells}

Nonpyramidal cells could be differentiated into basket cells innervating somata frequently and the other non-basket cells (Fig. $1 \mathrm{~J})$. Basket cells include several types different in their firing patterns, axon branching, elongation, and chemical characteristics (Fig. 2, 3). FS basket cells innervate spines as well as dendritic shafts, in addition to the multiple axonal boutons on other somata (Thomson et al., 1996; Tamás et al., 1997; Kawaguchi and Kubota, 1998). Thus, basket cells have a preference to innervate somata but also other structures. Some preference for somatic innervation is common to basket cell subtypes, but the selectivity of other structures may be diverse among the subtypes (White, 1989; Somogyi et al., 1998). Therefore, somata receive functionally heterogeneous GABAergic inputs. Large basket cells innervate a horizontally and vertically more diffuse field with longer internode intervals than FS, small, and descending basket cells. The innervation of small and descending basket cells is more compact in horizontal spread than FS and large basket cells. That is, each type of basket cells has a distinct territory in relation to the laminar and columnar structure. FS basket cells in layer II/III were more compact in the axonal field and larger in the maximum bouton density than those in layer $\mathrm{V}$. The former may correspond to nest basket cells (Wang et al., 2002). LS basket cells may be heterogeneous or belong to a subtype of CCK large basket cell because of their morphological similarity. Descending basket cells are thought to correspond to columnar basket cells (Szentágothai, 1975). The parameter resemblance in addition to the common chemical markers suggests a functional similarity between small and descending basket cells, with the descending ones mediating interlaminar inhibition.

\section{Chandelier and neurogliaform cells}

Chandelier and neurogliaform cells were similar in morphometric values and innervate densely near their somata with short interbouton intervals. However, the postsynaptic selectivity and inhibitory actions are different. Chandelier cells exert local inhibition on their specific target, axon initial segments (Somogyi et al., 1982; Somogyi, 1977), but neurogliaform cells may induce different types of inhibitory potentials, including slow inhibition, on diverse types of postsynaptic structures (Tamás et al., 2003). The differences in target selectivity, firing pattern, and IPSP kinetics suggest a functional diversity in short-range inhibition in the cortex.

\section{Martinotti and double bouquet cells}

These cells had different preferences in their vertical innervation direction. Martinotti cells with ascending arbors had more diffuse axonal fields with shorter interbouton and longer internode intervals than double bouquet cells with descending arbors. In addition to the vertical direction preference, the distinct differences in the innervation territory, axon branching, and bouton formation suggests a functional difference between them, al- 
though both participate in interlayer inhibition, innervating the postsynaptic structures other than somata.

\section{Conclusion}

Distributions of branching angles and internode and interbouton intervals were fitted to a particular probability density function irrespective of the subtypes. This suggests that nonpyramidal cells have a common mechanism of axon branching and bouton arrangement. Synaptic boutons, including those of chandelier cells, distributed randomly, except that at very short distances they were constrained by the finite bouton length. A single bouton could make two synaptic junctions to innervate two different synaptic targets, suggesting that the synaptic junctions distribute randomly along the axon, even at shorter distances than interbouton ones. This type of synapse distribution may reflect the spatially random placement of specific targets, the different influences from individual targets, or the inherent irregularity of presynaptic synapse formation. Each morphological subtype shows a characteristic combination of (1) the spatial distribution of boutons characterized by their horizontal and vertical spread around the soma, and (2) the local axon phenotypes represented mainly by the internode intervals, interbouton intervals, and vertical direction preference, indicating marked functional differences in the laminar and columnar selectivity of inhibition as well as in the subtype-specific density of inhibited targets.

\section{References}

Amir Y, Harel M, Malach R (1993) Cortical hierarchy reflected in the organization of intrinsic connections in macaque monkey visual cortex. J Comp Neurol 334:19-46.

Amitai Y, Connors BW (1995) Intrinsic physiology and morphology of single neurons in neocortex. In: Cerebral cortex, Vol 11, The barrel cortex of rodents (Jones EG, Diamond IT, eds), pp 299-331. New York: Plenum.

Anderson J, Binzegger T, Douglas R, Martin K (2002) Chance or design? Some specific considerations concerning specific boutons in cat visual cortex. J Neurocytol 31:211-229.

Braitenberg V, Schütz A (1998) Cortex: statistics and geometry of neural connectivity. Berlin: Springer.

Buhl E, Cobb S, Halasy K, Somogyi P (1995) Properties of unitary IPSPs evoked by anatomically identified basket cells in the rat hippocampus. Eur J Neurosci 7:1989-2004.

Burke RE, Marks WB (2002) Some approaches to quantitative dendritic morphology. In: Computational neuroanatomy: principles and methods (Ascoli AA, ed), pp 27-48. Totowa, NJ: Humana.

Cauli B, Audinat E, Lambolez B, Angulo MC, Ropert N, Tsuzuki K, Hestrin S, Rossier J (1997) Molecular and physiological diversity of cortical nonpyramidal cells. J Neurosci 17:3894-3906.

Cauli B, Porter JT, Tsuzuki K, Lambolez B, Rossier J, Quenet B, Audinat E (2000) Classification of fusiform neocortical interneurons based on unsupervised clustering. Proc Natl Acad Sci USA 97:6144-6149.
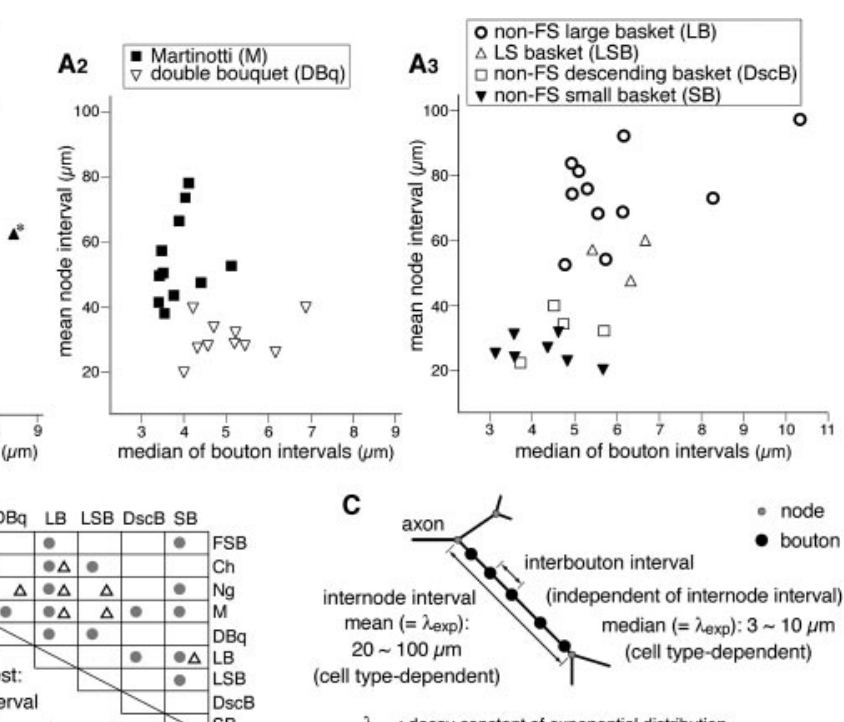

$\lambda$ exp: decay constant of exponential distribution

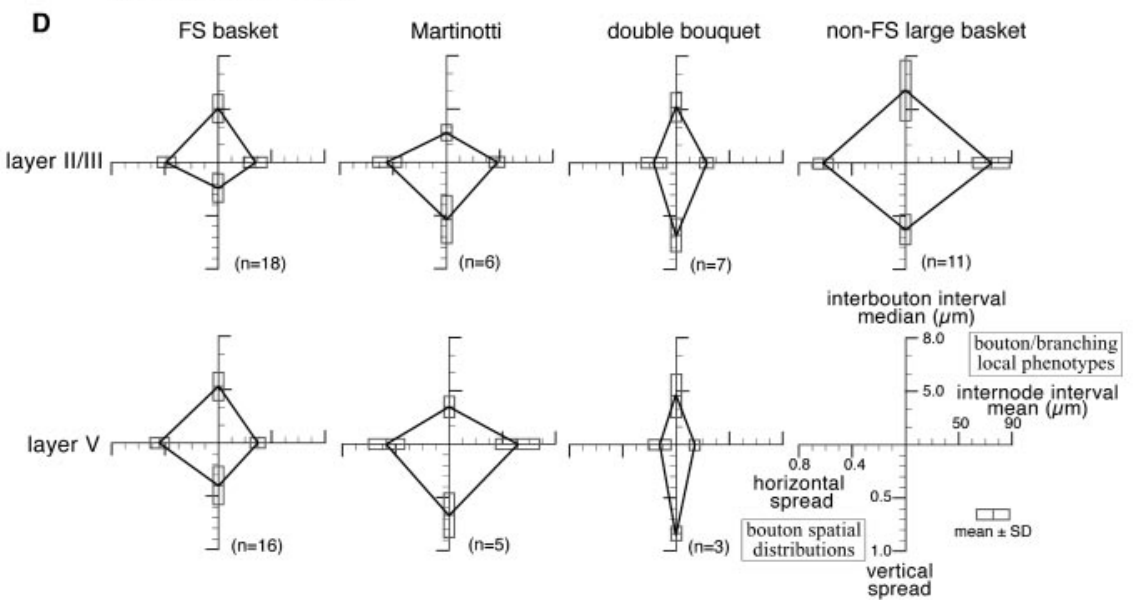

Figure 9. A, Relationships of the internode interval (mean) and the interbouton interval (median) of nonpyramidal cell subtypes. A1, FS basket, FS chandelier, and LS neurogliaform cells. *, neurogliaform cell with sparse innervation. A2, Martinotti a double bouquet cells. A3, Small, descending, large, and LS basket cells. Each subtype showed a distinct combination of the

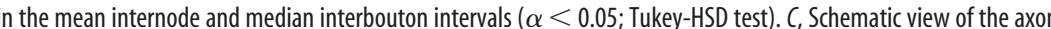

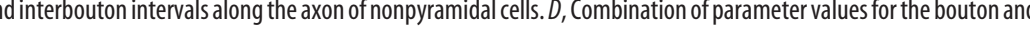

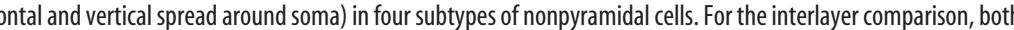
layer II/III and V cells are shown for FS basket, Martinotti, and double bouquet cells. Note that a characteristic association of four parameters in each subtype and the similarity between layer II/III and V cells.

DeFelipe J (1997) Types of neurons, synaptic connections and chemical characteristics of cells immunoreactive for calbindin-D28K, parvalbumin and calretinin in the neocortex. J Chem Neuroanat 14:1-19.

DeFelipe J, Fariñas I (1992) The pyramidal neuron of the cerebral cortex: morphological and chemical characteristics of the synaptic inputs. Prog Neurobiol 39:563-607.

Demeulemeester H, Vandesande F, Orban G, Brandon C, Vanderhaeghen J (1988) Heterogeneity of GABAergic cells in cat visual cortex. J Neurosci 8:988-1000.

Fairén A, DeFelipe J, Regidor J (1984) Nonpyramidal neurons: general account. In: Cerebral cortex, Vol 1, Cellular components of the cerebral cortex (Peters A, Jones EG, eds), pp 201-253. New York: Plenum.

Feldman M, Peters A (1978) The forms of non-pyramidal neurons in the visual cortex of the rat. J Comp Neurol 179:761-793.

Freund TF, Martin KA, Smith AD, Somogyi P (1983) Glutamate decarboxylase-immunoreactive terminals of Golgi-impregnated axoaxonic cells and of presumed basket cells in synaptic contact with pyramidal neurons of the cat's visual cortex. J Comp Neurol 221:263-278. 
Gonchar Y, Burkhalter A (1997) Three distinct families of GABAergic neurons in rat visual cortex. Cereb Cortex 7:347-358.

Gupta A, Wang Y, Markram H (2000) Organizing principles for a diversity of GABAergic interneurons and synapses in the neocortex. Science 287:273-278.

Hellwig B, Schüz A, Aertsen A (1994) Synapses on axon collaterals of pyramidal cells are spaced at random intervals: a Golgi study in the mouse cerebral cortex. Biol Cybern 71:1-12.

Houser CR, Hendry SHC, Jones EG, Vaughn VE (1983) Morphological diversity of immunocytochemically identified GABA neurons in monkey sensory-motor cortex. J Neurocytol 12:617-638.

Jones EG (1975) Varieties and distribution of non-pyramidal cells in the somatic sensory cortex of the squirrel monkey. J Comp Neurol 160:205-267.

Jones EG (1984a) Neurogliaform or spiderweb cells. In: Cerebral cortex, Vol 1, Cellular components of the cerebral cortex (Peters A, Jones EG, eds), pp 409-418. New York: Plenum.

Jones EG (1984b) Laminar distribution of output cells. In: Cerebral cortex, Vol 1, Cellular components of the cerebral cortex (Peters A, Jones EG, eds), pp 521-553. New York: Plenum.

Kawaguchi Y (1993) Groupings of nonpyramidal and pyramidal cells with specific physiological and morphological characteristics in rat frontal cortex. J Neurophysiol 69:416-431.

Kawaguchi Y (1995) Physiological subgroups of nonpyramidal cells with specific morphological characteristics in layer II/III of rat frontal cortex. J Neurosci 15:2638-2655.

Kawaguchi Y (2001) Distinct firing patterns of neuronal subtypes in cortical synchronized activities. J Neurosci 21:7261-7272.

Kawaguchi Y (2003) Local circuit neurons in the frontal cortico-striatal system. In: Excitatory-inhibitory balance: synapses, circuits, and systems plasticity (Hensch T, Fagiolini M, eds), pp 125-148. New York: Kluwer Academic/Plenum.

Kawaguchi Y, Kondo S (2002) Parvalbumin, somatostatin and cholecystokinin as chemical markers for specific GABAergic interneuron types in the rat frontal cortex. J Neurocytol 31:277-287.

Kawaguchi Y, Kubota Y (1996) Physiological and morphological identification of somatostatin- or vasoactive intestinal polypeptide-containing cells among GABAergic cell subtypes in rat frontal cortex. J Neurosci 16:2701-2715.

Kawaguchi Y, Kubota Y (1997) GABAergic cell subtypes and their synaptic connections in rat frontal cortex. Cereb Cortex 7:476-486.

Kawaguchi Y, Kubota Y (1998) Neurochemical features and synaptic connections of large physiologically-identified GABAergic cells in the rat frontal cortex. Neuroscience 85:677-701.

Kincaid AE, Zheng T, Wilson CJ (1998) Connectivity and convergence of single corticostriatal axons. J Neurosci 18:4722-4731.

Kisvárday ZF, Martin KA, Whitteridge D, Somogyi P (1985) Synaptic connections of intracellularly filled clutch cells: a type of small basket cell in the visual cortex of the cat. J Comp Neurol 241:111-137.

Kubota Y, Kawaguchi Y (1997) Two distinct subgroups of cholecystokininimmunoreactive cortical interneurons. Brain Res 752:175-183.

Kubota Y, Kawaguchi Y (2000) Dependence of GABAergic synaptic areas on the interneuron type and target size. J Neurosci 20:375-386.
Kubota Y, Hattori R, Yui Y (1994) Three distinct subpopulations of GABAergic neurons in rat frontal agranular cortex. Brain Res 649:159-173.

Morrison J, Magistretti P, Benoit R, Bloom F (1984) The distribution and morphological characteristics of the intracortical VIP-positive cell: an immunohistochemical analysis. Brain Res 292:269-282.

Peters A (1984) Chandelier cells. In: Cerebral Cortex, Vol 1, Cellular components of the cerebral cortex (Peters A, Jones EG, eds), pp 361-380. New York: Plenum.

Ramón y Cajal S (1911) Histology of the nervous system, Vol 2 (Swanson N, Swanson LW, translators) New York: Oxford UP.

Ribak CE (1978) Aspinous and sparsely-spinous stellate neurons in the visual cortex of rats contain glutamic acid decarboxylase. J Neurocytol 7:461-478.

Shepherd G, Harris K (1998) Three-dimensional structure and composition of $\mathrm{CA} 3 \rightarrow \mathrm{CA} 1$ axons in rat hippocampal slices: implications for presynaptic connectivity and compartmentalization. J Neurosci 18:8300-8310.

Shepherd G, Raastad M, Andersen P (2002) General and variable features of varicosity spacing along unmyelinated axons in the hippocampus and cerebellum. Proc Natl Acad Sci USA 99:6340-6345.

Silberberg G, Gupta A, Markram H (2002) Stereotypy in neocortical microcircuits. Trends Neurosci 25:227-230.

Somogyi P (1977) A specific "axo-axonal” interneuron in the visual cortex of the rat. Brain Res 136:345-350.

Somogyi P, Freund TF, Cowey A (1982) The axo-axonic interneuron in the cerebral cortex of the rat, cat and monkey. Neuroscience 7:2577-2607.

Somogyi P, Tamás G, Luján R, Buhl EH (1998) Salient features of synaptic organisation in the cerebral cortex. Brain Res Rev 26:113-135.

Szentágothai J (1975) The "module-concept" in cerebral cortex architecture. Brain Res 95:475-496.

Tamás G, Buhl E, Somogyi P (1997) Fast IPSPs elicited via multiple synaptic release sites by different types of GABAergic neurone in the cat visual cortex. J Physiol (Lond) 500:715-738.

Tamás G, Lörincz A, Simon A, Szabadics J (2003) Identified sources and targets of slow inhibition in the neocortex. Science 299:1902-1905.

Tettoni L, Lehmann P, Houzel J-C, Innocenti GM (1996) Maxsim, software for the analysis of multiple axonal arbors and their simulated activation. J Neurosci Methods 67:1-9.

Tettoni L, Gheorghita-Baechler F, Bressoud R, Welker E, Innocenti G (1998) Constant and variable aspects of axonal phenotype in cerebral cortex. Cereb Cortex 8:543-552.

Thomson A, West DC, Hahn J, Deuchars J (1996) Single axon IPSPs elicited in pyramidal cells by three classes of interneurones in slices of rat neocortex. J Physiol (Lond) 496:81-102.

Wang Y, Gupta A, Toledo-Rodriguez M, Wu CZ, Markram H (2002) Anatomical, physiological, molecular and circuit properties of nest basket cells in the developing somatosensory cortex. Cereb Cortex 12:395-410.

White EL (1989) Cortical circuits: synaptic organization of the cerebral cortex structure, function, and theory. Boston: Birkhäuser.

Winfield DA, Rivera-Dominguez M, Powell TPS (1981) The number and distribution of Meynert cells in area 17 of the macaque monkey. Proc R Soc Lond B Biol Sci 213:27-40. 